\title{
Strong Convergence Theorems for Solutions of Equations of Hammerstein Type
}

\author{
Chih-Sheng Chuang \\ Department of Mathematics, National Cheng Kung University, Tainan 701, Taiwan \\ Correspondence should be addressed to Chih-Sheng Chuang; cschuang1977@gmail.com
}

Received 11 March 2013; Accepted 18 April 2013

Academic Editor: Erdal Karapınar

Copyright (c) 2013 Chih-Sheng Chuang. This is an open access article distributed under the Creative Commons Attribution License, which permits unrestricted use, distribution, and reproduction in any medium, provided the original work is properly cited.

\begin{abstract}
We consider an auxiliary operator, defined in a real Hilbert space in terms of $K$ and $F$, that is, monotone and Lipschitz mappings (resp., monotone and bounded mappings). We use an explicit iterative process that converges strongly to a solution of equation of Hammerstein type. Furthermore, our results improve related results in the literature.
\end{abstract}

\section{Introduction}

Let $H$ be a real Hilbert space. A mapping $A: D(A) \subseteq H \rightarrow$ $H$ is said to be monotone if $\langle A x-A y, x-y\rangle \geq 0$ for every $x, y \in D(A)$. $A$ is called maximal monotone if it is monotone and the $R(I+r A)=H$, the range of $(I+r A)$, for each $r>0$, where $I$ is the identity mapping on $H$. $A$ is said to satisfy the range condition if $\operatorname{cl}(D(A)) \subseteq R(I+r A)$ for each $r>0$. For monotone mappings, there are many related equations of evolution. Several problems that arise in differential equations, for instance, elliptic boundary value problems whose linear parts possess Green's function, can be put in operator form as

$$
u+K F u=0,
$$

where $K$ and $F$ are monotone mappings. In fact, (1) comes from the following integral equation of Hammerstein type [1]:

$$
u(x)+\int_{\Omega} k(x, y) f(y, u(y)) d y=h(x),
$$

where $d y$ is a $\sigma$-finite measure on the measure space $\Omega$; the real kernel is defined by $\Omega \times \Omega, f$ is a real-valued function defined on $\Omega \times \mathbb{R}$ and is, in general, nonlinear, and $h$ is a given function on $\Omega$. If we now define an operator $K$ by

$$
K v(x)=\int_{\Omega} k(x, y) v(y) d y, \quad x \in \Omega,
$$

and the so-called superposition or Nemytskii operator by $F u(y):=f(y, u(y))$, then (2) can be put in (1) (without loss of generality, we may assume that $h \equiv 0)$.

Note that equations of Hammerstein type play a crucial role in the theory of optimal control systems and in automation and network theory, and several existence and uniqueness theorems have been proved for equations of the Hammerstein type. For details, one can refer to [2-7].

In 2005, Chidume and Zegeye [8] constructed an iterative process as follows:

$$
\begin{gathered}
u_{n+1}=u_{n}-\lambda_{n}\left(F u_{n}-v_{n}\right)-\lambda_{n} \theta_{n}\left(u_{n}-w\right), \\
v_{n+1}=v_{n}-\lambda_{n}\left(K v_{n}+u_{n}\right)-\lambda_{n} \theta_{n}\left(v_{n}-w\right), \quad n \in \mathbb{N},
\end{gathered}
$$

where $H$ is a real Hilbert space, $F$ and $K: H \rightarrow H$ are bounded monotone mappings satisfying the range condition, $w \in H$, and $\left\{\lambda_{n}\right\}_{n \in \mathbb{N}}$ and $\left\{\theta_{n}\right\}_{n \in \mathbb{N}}$ are sequences in $(0,1)$. Chidume and Zegeye [8] show that this sequence converges strongly to the solution of (1) under suitable conditions.

In 2011, Chidume and Ofoedu [9] introduced a coupled explicit iterative process as follows:

$$
\begin{gathered}
u_{n+1}=u_{n}-\lambda_{n} \alpha_{n}\left(F u_{n}-v_{n}\right)-\lambda_{n} \theta_{n}\left(u_{n}-u_{1}\right), \\
v_{n+1}=v_{n}-\lambda_{n} \alpha_{n}\left(K v_{n}+u_{n}\right)-\lambda_{n} \theta_{n}\left(v_{n}-v_{1}\right), \quad n \in \mathbb{N},
\end{gathered}
$$

where $E$ is a uniformly smooth real Banach space, $F$ and $K$ : $E \rightarrow E$ are bounded and monotone mappings, and $\left\{\lambda_{n}\right\}_{n \in \mathbb{N}}$, 
$\left\{\theta_{n}\right\}_{n \in \mathbb{N}}$, and $\left\{\alpha_{n}\right\}_{n \in \mathbb{N}}$ are sequences in $(0,1)$. Chidume and Ofoedu [9] gave a strong convergence theorem for approximation of the solution of (1) under suitable conditions.

In 2012, Chidume and Djitté [10] consider the following iterative process:

$$
\begin{gathered}
u_{n+1}=u_{n}-\lambda_{n}\left(F u_{n}-v_{n}\right)-\lambda_{n} \theta_{n}\left(u_{n}-u_{1}\right), \\
v_{n+1}=v_{n}-\lambda_{n}\left(K v_{n}+u_{n}\right)-\lambda_{n} \theta_{n}\left(v_{n}-v_{1}\right), \quad n \in \mathbb{N},
\end{gathered}
$$

where $H$ is a real Hilbert space, $K$ and $F$ are bounded and maximal monotone mappings, $\left\{\lambda_{n}\right\}_{n \in \mathbb{N}}$ and $\left\{\theta_{n}\right\}_{n \in \mathbb{N}}$ are sequences in $(0,1)$ and Chidume and Djitté $[10]$ show that this iterative process converges to an approximate solution of nonlinear equations of Hammerstein type under suitable conditions.

Motivated by the previous works, in this paper, we consider an auxiliary operator, defined in a real Hilbert space in terms of $K$ and $F$, that is monotone and Lipschitz mapping, or monotone and bounded mappings. We use an explicit iterative process that converges strongly to a solution of equation of Hammerstein type. Furthermore, our results improve related results in the literature.

\section{Preliminaries}

Throughout this paper, let $\mathbb{N}$ be the set of positive integers and let $\mathbb{R}$ be the set of real numbers. Let $H$ be a (real) Hilbert space with inner product $\langle\cdot, \cdot\rangle$ and norm $\|\cdot\|$, respectively.

Lemma 1. Let $H$ be a real Hilbert space. One has $\|x+y\|^{2} \leq$ $\|x\|^{2}+2\langle y, x+y\rangle$ for all $x, y \in H$.

Lemma 2 (see [11]). Let $\left\{a_{n}\right\}_{n \in \mathbb{N}}$ be a sequence of nonnegative real numbers, $\left\{\alpha_{n}\right\}_{n \in \mathbb{N}}$ a sequence of real numbers in $[0,1]$ with $\sum_{n=1}^{\infty} \alpha_{n}=\infty$, and $\left\{u_{n}\right\}_{n \in \mathbb{N}}$ a sequence of nonnegative real numbers with $\sum_{n=1}^{\infty} u_{n}<\infty,\left\{t_{n}\right\}_{n \in \mathbb{N}}$ a sequence of real numbers with $\lim \sup t_{n} \leq 0$. Suppose that $a_{n+1} \leq\left(1-\alpha_{n}\right) a_{n}+\alpha_{n} t_{n}+u_{n}$ for each $n \in \mathbb{N}$. Then, $\lim _{n \rightarrow \infty} a_{n}=0$.

Let $\ell^{\infty}$ be the Banach space of bounded sequences with the supremum norm. A linear functional $\mu$ on $\ell^{\infty}$ is called a mean if $\mu(e)=\|\mu\|=1$, where $e=(1,1,1, \ldots)$. For $x=\left(x_{1}\right.$, $\left.x_{2}, x_{3}, \ldots\right)$, the value $\mu(x)$ is also denoted by $\mu_{n}\left(x_{n}\right)$. A mean $\mu$ on $\ell^{\infty}$ is called a Banach limit if it satisfies $\mu_{n}\left(x_{n}\right)=\mu_{n}\left(x_{n+1}\right)$. If $\mu$ is a Banach limit on $\ell^{\infty}$, then for $x=\left(x_{1}, x_{2}, x_{3}, \ldots\right) \in \ell^{\infty}$,

$$
\liminf _{n \rightarrow \infty} x_{n} \leq \mu_{n}\left(x_{n}\right) \leq \limsup _{n \rightarrow \infty} x_{n}
$$

In particular, if $x=\left(x_{1}, x_{2}, x_{3}, \ldots\right) \in \ell^{\infty}$ and $\lim _{n \rightarrow \infty} x_{n}=$ $a \in \mathbb{R}$, then we have $\mu(x)=\mu_{n}\left(x_{n}\right)=a$. For details, we can refer to [12].

Lemma 3 (see [13]). Let $\alpha$ be a real number and $\left(x_{0}, x_{1}, \ldots\right) \in$ $\ell^{\infty}$ such that $\mu_{n} x_{n} \leq \alpha$ for all Banach limit $\mu$ on $\ell^{\infty}$. If $\limsup _{n \rightarrow \infty}\left(x_{n+1}-x_{n}\right) \leq 0$, then, $\limsup _{n \rightarrow \infty} x_{n} \leq \alpha$.

Lemma 4 (see [14]). Let $C$ be a nonempty closed convex subset of a Hilbert space $H$, let $\left\{x_{n}\right\}_{n \in \mathbb{N}}$ be a bounded sequence in $H$, and let $\mu$ be a Banach limit on $\ell^{\infty}$. Let $g: C \rightarrow \mathbb{R}$ be defined by $g(z)=\mu_{n}\left\|x_{n}-z\right\|^{2}$ for each $z \in C$. Then there exists a unique $z_{0} \in C$ such that $g\left(z_{0}\right)=\min \{g(z): z \in C\}$.

Lemma 5 (see [15]). Let $H$ be a Hilbert space, let $\left\{x_{n}\right\}_{n \in \mathbb{N}}$ be a bounded sequence in $H$, and let $\mu$ be a mean on $\ell^{\infty}$. Then, there exists a unique point $z_{0} \in H$ such that $\mu_{n}\left\langle x_{n}, y\right\rangle=\left\langle z_{0}, y\right\rangle$ for each $y \in H$. Indeed, $z_{0} \in \overline{\operatorname{co}}\left\{x_{n}: n \in \mathbb{N}\right\}$.

Let $H$ be a real Hilbert space. Let $W:=H \times H$ with norm

$$
\|z\|:=\left(\|u\|^{2}+\|v\|^{2}\right)^{1 / 2}, \quad \text { where } z=(u, v) \in W
$$

Hence, $W$ is a real Hilbert space with inner product $\left\langle w_{1}\right.$, $\left.w_{2}\right\rangle=\left\langle u_{1}, u_{2}\right\rangle+\left\langle v_{1}, v_{2}\right\rangle$ for all $w_{1}=\left(u_{l}, v_{1}\right), w_{2}=\left(u_{2}, v_{2}\right) \in$ $W[8]$.

Lemma 6. Let $H$ be a real Hilbert space, and let $W:=H \times H$. Let $F, K: H \rightarrow H$ be two mappings, and let $A: W \rightarrow W$ be defined by

$$
A w:=(F u-v, K v+u) \quad \text { for each } w=(u, v) \in W .
$$

(i) If $F$ and $K$ are monotone mappings, then $A$ is a monotone mapping [8, Lemma 3.1].

(ii) If $F$ and $K$ are bounded mappings, then $A$ is a bounded mapping [8, Lemma 3.1].

(iii) If $F$ and $K$ are Lipschitz mappings with Lipschitz constants $L_{1}$ and $L_{2}$, respectively, then $A$ is a Lipschitz mapping. Indeed, the Lipschitz constant of $A$ is $2(L+1)$, where $L:=\max \left\{L_{1}, L_{2}\right\}[16$, Remark 13.6].

\section{Main Results (I)}

Let $H$ be a real Hilbert space. Let $F, K: H \rightarrow H$ be two mappings, and let $A: H \times H \rightarrow H \times H$ be defined by $A w=$ $(F u-v, K v+u)$ for each $w=(u, v) \in H \times H$. Then, we observe that $\bar{u} \in H$ is a solution of $u+K F u=0$ if and only if $\bar{w}=(\bar{u}, \bar{v})$ is a solution of $A w=0$ in $H \times H$ for $\bar{v}=F \bar{u}$.

Theorem 7. Let $H$ be a real Hilbert space. Let $F, K: H \rightarrow H$ be Lipschitz and monotone mappings. Suppose that $u+K F u=$ 0 has a solution in $H$. Let $\left\{\lambda_{n}\right\}_{n \in \mathbb{N}}$ be a sequence in $(0,1)$. Let $\left\{\alpha_{n}\right\}_{n \in \mathbb{N}}$ and $\left\{\theta_{n}\right\}_{n \in \mathbb{N}}$ be sequences in $(0,1]$. Let $\left\{u_{n}\right\}_{n \in \mathbb{N}}$ and $\left\{v_{n}\right\}_{n \in \mathbb{N}}$ be sequences in $H$ defined iteratively from arbitrary $u_{1}$, $v_{1} \in H$ by

$$
\begin{gathered}
u_{n+1}=u_{n}-\lambda_{n} \alpha_{n}\left(F u_{n}-v_{n}\right)-\lambda_{n} \theta_{n}\left(u_{n}-u_{1}\right), \\
v_{n+1}=v_{n}-\lambda_{n} \alpha_{n}\left(K v_{n}+u_{n}\right)-\lambda_{n} \theta_{n}\left(v_{n}-v_{1}\right), \quad n \in \mathbb{N} .
\end{gathered}
$$


Suppose that one of the following conditions holds:

$$
\begin{aligned}
& \text { (i) } \lim _{n \rightarrow \infty}\left(\frac{\alpha_{n}^{2}}{\theta_{n}}\right)=\lim _{n \rightarrow \infty} \lambda_{n} \alpha_{n}=0 ; \\
& \text { (ii) } \lim _{n \rightarrow \infty}\left(\frac{\lambda_{n}}{\theta_{n}}\right)=0 ; \\
& \text { (iii) } \lim _{n \rightarrow \infty}\left(\frac{\alpha_{n}}{\theta_{n}}\right)=0 .
\end{aligned}
$$

Then, the sequences $\left\{u_{n}\right\}_{n \in \mathbb{N}},\left\{v_{n}\right\}_{n \in \mathbb{N}},\left\{F u_{n}\right\}_{n \in \mathbb{N}}$, and $\left\{K v_{n}\right\}_{n \in \mathbb{N}}$ are bounded.

Proof. Since $F$ and $K$ are Lipschitz mappings, we may assume that the Lipschitz constants of $F$ and $K$ are $L_{1}$ and $L_{2}$, respectively. Let

$$
L=\max \left\{L_{1}, L_{2}\right\}, \quad r_{0}:=\frac{1}{32(L+1)^{2}} .
$$

Let $W:=H \times H$ with the norm $\|w\|:=\left(\|u\|^{2}+\|v\|^{2}\right)^{1 / 2}$ for each $w=(u, v) \in H \times H$. Take any $\bar{u} \in H$ such that $\bar{u}$ is solution of $u+K F u=0$, and let $\bar{u}$ be fixed. Let $\bar{v}=F \bar{u}$ and $\bar{w}=(\bar{u}, \bar{v})$. We observe that $\bar{u}=-K \bar{v}$. For each $n \in \mathbb{N}$, let $w_{n}:=\left(u_{n}, v_{n}\right)$.

For each $n \in \mathbb{N}$, it follows from Lemma 1 that

$$
\begin{aligned}
&\left\|u_{n+1}-\bar{u}\right\|^{2} \\
&=\left\|\left(1-\lambda_{n} \theta_{n}\right)\left(u_{n}-\bar{u}\right)+\lambda_{n}\left(\theta_{n} u_{1}-\alpha_{n} F u_{n}+\alpha_{n} v_{n}-\theta_{n} \bar{u}\right)\right\|^{2} \\
& \leq\left(1-\lambda_{n} \theta_{n}\right)^{2}\left\|u_{n}-\bar{u}\right\|^{2} \\
&+2 \lambda_{n}\left\langle\theta_{n} u_{1}-\alpha_{n} F u_{n}+\alpha_{n} v_{n}-\theta_{n} \bar{u}, u_{n+1}-\bar{u}\right\rangle \\
& \leq\left(1-\lambda_{n} \theta_{n}\right)\left\|u_{n}-\bar{u}\right\|^{2} \\
&+2 \lambda_{n}\left\langle\theta_{n} u_{1}-\alpha_{n} F u_{n}+\alpha_{n} v_{n}-\theta_{n} \bar{u}, u_{n+1}-\bar{u}\right\rangle .
\end{aligned}
$$

Similarly, we have

$$
\begin{aligned}
\| v_{n+1} & -\bar{v} \|^{2} \\
\leq & \left(1-\lambda_{n} \theta_{n}\right)\left\|v_{n}-\bar{v}\right\|^{2} \\
\quad & +2 \lambda_{n}\left\langle\theta_{n} v_{1}-\alpha_{n} K v_{n}-\alpha_{n} u_{n}-\theta_{n} \bar{u}, v_{n+1}-\bar{v}\right\rangle .
\end{aligned}
$$

For each $n \in \mathbb{N}$, by (13) and (14), we know that

$$
\begin{aligned}
\| w_{n+1}- & \bar{w} \|^{2} \\
\leq & \left(1-\lambda_{n} \theta_{n}\right)\left\|w_{n}-\bar{w}\right\|^{2} \\
& +2 \lambda_{n}\left\langle\theta_{n} w_{1}-\alpha_{n} A w_{n}-\theta_{n} \bar{w}, w_{n+1}-\bar{w}\right\rangle \\
= & \left(1-\lambda_{n} \theta_{n}\right)\left\|w_{n}-\bar{w}\right\|^{2}+2 \lambda_{n} \theta_{n}\left\langle w_{1}-\bar{w}, w_{n+1}-\bar{w}\right\rangle \\
& -2 \lambda_{n} \alpha_{n}\left\langle A w_{n}, w_{n+1}-\bar{w}\right\rangle .
\end{aligned}
$$

For each $n \in \mathbb{N}$, since $A$ is monotone and $A \bar{w}=0$, we know that

$$
\begin{aligned}
& \left\langle A w_{n}, w_{n+1}-\bar{w}\right\rangle \\
& \quad=\left\langle A w_{n}, w_{n}-\lambda_{n} \alpha_{n} A w_{n}-\lambda_{n} \theta_{n}\left(w_{n}-w_{1}\right)-\bar{w}\right\rangle \\
& \quad=\left\langle A w_{n}, w_{n}-\bar{w}\right\rangle+\left\langle A w_{n},-\lambda_{n} \alpha_{n} A w_{n}-\lambda_{n} \theta_{n}\left(w_{n}-w_{1}\right)\right\rangle \\
& \quad \geq\left\langle A w_{n},-\lambda_{n} \alpha_{n} A w_{n}-\lambda_{n} \theta_{n}\left(w_{n}-w_{1}\right)\right\rangle .
\end{aligned}
$$

Hence, for each $n \in \mathbb{N}$, it follows from (15) and (16) that

$$
\begin{aligned}
\| w_{n+1}- & \bar{w} \|^{2} \\
\leq & \left(1-\lambda_{n} \theta_{n}\right)\left\|w_{n}-\bar{w}\right\|^{2}+2 \lambda_{n} \theta_{n}\left\langle w_{1}-\bar{w}, w_{n+1}-\bar{w}\right\rangle \\
& -2 \lambda_{n} \alpha_{n}\left\langle A w_{n}, w_{n+1}-\bar{w}\right\rangle \\
\leq & \left(1-\lambda_{n} \theta_{n}\right)\left\|w_{n}-\bar{w}\right\|^{2}+2 \lambda_{n} \theta_{n}\left\langle w_{1}-\bar{w}, w_{n+1}-\bar{w}\right\rangle \\
& +2 \lambda_{n} \alpha_{n}\left\langle A w_{n}, \lambda_{n} \alpha_{n} A w_{n}+\lambda_{n} \theta_{n} w_{n}-\lambda_{n} \theta_{n} w_{1}\right\rangle \\
\leq & \left(1-\lambda_{n} \theta_{n}\right)\left\|w_{n}-\bar{w}\right\|^{2}+2 \lambda_{n} \theta_{n}\left\langle w_{1}-\bar{w}, w_{n+1}-\bar{w}\right\rangle \\
& +2 \lambda_{n} \alpha_{n}\left\|A w_{n}\right\| \cdot\left(\lambda_{n} \alpha_{n}\left\|A w_{n}\right\|+\lambda_{n} \theta_{n}\left\|w_{n}-w_{1}\right\|\right) \\
\leq & \left(1-\lambda_{n} \theta_{n}\right)\left\|w_{n}-\bar{w}\right\|^{2}+2 \lambda_{n} \theta_{n}\left\langle w_{1}-\bar{w}, w_{n+1}-\bar{w}\right\rangle \\
& +4 \lambda_{n} \alpha_{n}(L+1)\left\|w_{n}-\bar{w}\right\| \\
& +\left(2 \lambda_{n} \alpha_{n}(L+1)\left\|w_{n}-\bar{w}\right\|+\lambda_{n} \theta_{n}\left\|w_{n}-w_{1}\right\|\right) \\
= & \left(1-\lambda_{n} \theta_{n}\right)\left\|w_{n}-\bar{w}\right\|^{2}+2 \lambda_{n} \theta_{n}\left\langle w_{1}-\bar{w}, w_{n+1}-\bar{w}\right\rangle \\
& +8 \lambda_{n}^{2} \alpha_{n}^{2}(L+1)^{2}\left\|w_{n}-\bar{w}\right\|^{2} \\
& +4 \lambda_{n}^{2} \alpha_{n} \theta_{n}(L+1)\left\|w_{n}-\bar{w}\right\| \cdot\left\|w_{n}-w_{1}\right\| \cdot
\end{aligned}
$$

For conditions (i)-(iii), we only need to consider one case since the proof is similar. Now, we assume that $\lim _{n \rightarrow \infty}\left(\lambda_{n} / \theta_{n}\right)=0$. Then, there exists $n_{0} \in \mathbb{N}$ such that $\lambda_{n} /$ $\theta_{n}<r_{0}$ for each $n \geq n_{0}$. Choose $r>0$ such that $w_{1} \in B(\bar{w}, r / 4)$ and $w_{n_{0}} \in B(\bar{w}, r / 4)$. Let $B:=\overline{B(\bar{w}, r)}$.

Now, we want to show that $w_{n} \in B$ for each $n \geq n_{0}$. Clearly, $w_{n_{0}} \in B(\bar{w}, r)$. Suppose that $w_{n} \in B$ for some $n \geq n_{0}$. Then, $w_{n+1} \in B$. Indeed, if not, then we have

$$
\left\|w_{n}-\bar{w}\right\| \leq r<\left\|w_{n+1}-\bar{w}\right\| .
$$

Hence, by (17) and (18), we get

$$
\begin{aligned}
\left\|w_{n+1}-\bar{w}\right\|^{2} \leq & \left(1-\lambda_{n} \theta_{n}\right)\left\|w_{n+1}-\bar{w}\right\|^{2} \\
& +2 \lambda_{n} \theta_{n}\left\|w_{1}-\bar{w}\right\| \cdot\left\|w_{n+1}-\bar{w}\right\| \\
& +8 \lambda_{n}^{2} \alpha_{n}^{2}(L+1)^{2}\left\|w_{n}-\bar{w}\right\| \cdot\left\|w_{n+1}-\bar{w}\right\| \\
& +4 \lambda_{n}^{2} \alpha_{n} \theta_{n}(L+1)\left\|w_{n+1}-\bar{w}\right\| \cdot\left\|w_{n}-w_{1}\right\| .
\end{aligned}
$$


By (19), we have

$$
\begin{aligned}
\lambda_{n} \theta_{n} \| & w_{n+1}-\bar{w} \| \\
\leq & 2 \lambda_{n} \theta_{n}\left\|w_{1}-\bar{w}\right\|+8 \lambda_{n}^{2} \alpha_{n}^{2}(L+1)^{2}\left\|w_{n}-\bar{w}\right\| \\
& +4 \lambda_{n}^{2} \alpha_{n} \theta_{n}(L+1)\left\|w_{n}-w_{1}\right\| \\
\leq & 2 \lambda_{n} \theta_{n} \cdot \frac{r}{4}+8 \lambda_{n}^{2} \alpha_{n}^{2}(L+1)^{2} r+4 \lambda_{n}^{2} \alpha_{n} \theta_{n}(L+1) \\
& \cdot\left(\left\|w_{n}-\bar{w}\right\|+\left\|w_{1}-\bar{w}\right\|\right) \\
\leq & 2 \lambda_{n} \theta_{n} \cdot \frac{r}{4}+8 \lambda_{n}^{2} \alpha_{n}^{2}(L+1)^{2} r+4 \lambda_{n}^{2} \alpha_{n} \theta_{n}(L+1) \cdot \frac{5 r}{4}
\end{aligned}
$$

This implies that

$$
\begin{aligned}
r & <\left\|w_{n+1}-\bar{w}\right\| \\
& \leq \frac{1}{2} r+8 \lambda_{n} \frac{\alpha_{n}^{2}}{\theta_{n}}(L+1)^{2} r+\frac{5 \lambda_{n} \alpha_{n} \theta_{n}}{\theta_{n}}(L+1) r \\
& \leq \frac{1}{2} r+\frac{8 \lambda_{n}}{\theta_{n}}(L+1)^{2} r+\frac{8 \lambda_{n}}{\theta_{n}}(L+1) r \\
& \leq r .
\end{aligned}
$$

This leads to a contradiction. So, $w_{n+1} \in B$. Hence, by mathematical induction, we know that $\left\{w_{n}\right\}_{n \geq n_{0}} \subseteq B$. Therefore, $\left\{u_{n}\right\}_{n \in \mathbb{N}}$ and $\left\{v_{n}\right\}_{n \in \mathbb{N}}$ are bounded sequences. Furthermore, $\left\{F u_{n}\right\}_{n \in \mathbb{N}}$ and $\left\{K v_{n}\right\}_{n \in \mathbb{N}}$ are bounded sequences since $F$ and $K$ are Lipschitz mappings. For conditions (ii) and (iii), the proof is similar. Therefore, the proof is completed.

Remark 8. (i) Theorem 7 improves the conditions of [17, Theorem 3.1] if the space $E$ in [17] is reduced to a real Hilbert space. Indeed, [17, Theorem 3.1] assumes that $\lim _{n \rightarrow \infty} \lambda_{n}=$ $\lim _{n \rightarrow \infty} \alpha_{n}=\lim _{n \rightarrow \infty}\left(\lambda_{n} / \theta_{n}\right)=\lim _{n \rightarrow \infty}\left(\alpha_{n} / \theta_{n}\right)=0$.

(ii) Furthermore, we know that it is impossible to assume that $\alpha_{n}=\theta_{n}=1$ in [17, Theorem 3.1]. However, we can choose $\alpha_{n}=\theta_{n}=1$ in our result. Indeed, if $\alpha_{n}=\theta_{n}=1$ and $\lambda_{n}=\beta_{n}$, then we have the following result as a special case of Theorem 7 .

Corollary 9. Let $H$ be a real Hilbert space. Let $F, K: H \rightarrow H$ be Lipschitz and monotone mappings. Suppose that $u+K F u=$ 0 has a solution in $H$. Let $\left\{\beta_{n}\right\}_{n \in \mathbb{N}}$ be a sequence in $(0,1)$. Let $\left\{u_{n}\right\}_{n \in \mathbb{N}}$ and $\left\{v_{n}\right\}_{n \in \mathbb{N}}$ be sequences in $H$ defined iteratively from arbitrary $u_{1}, v_{1} \in H$ by

$$
\begin{gathered}
u_{n+1}=u_{n}-\beta_{n}\left(F u_{n}-v_{n}\right)-\beta_{n}\left(u_{n}-u_{1}\right), \\
v_{n+1}=v_{n}-\beta_{n}\left(K v_{n}+u_{n}\right)-\beta_{n}\left(v_{n}-v_{1}\right), \quad n \in \mathbb{N} .
\end{gathered}
$$

If $\lim _{n \rightarrow \infty} \beta_{n}=0$, then the sequences $\left\{u_{n}\right\}_{n \in \mathbb{N}},\left\{v_{n}\right\}_{n \in \mathbb{N}}$, $\left\{F u_{n}\right\}_{n \in \mathbb{N}}$, and $\left\{K v_{n}\right\}_{n \in \mathbb{N}}$ are bounded.

In fact, following the same argument as the proof of Theorem 7, we can get the following result.
Theorem 10. Let $H$ be a real Hilbert space. Let $F, K: H \rightarrow H$ be Lipschitz and monotone mappings. Suppose that $u+K F u=$ 0 has a solution in $H$. Let $\left\{\alpha_{n}\right\}_{n \in \mathbb{N}}$ and $\left\{\theta_{n}\right\}_{n \in \mathbb{N}}$ be sequences in $(0,1]$. Let $\left\{u_{n}\right\}_{n \in \mathbb{N}}$ and $\left\{v_{n}\right\}_{n \in \mathbb{N}}$ be sequences in $H$ defined iteratively from arbitrary $u_{1}, v_{1} \in H$ by

$$
\begin{gathered}
u_{n+1}=u_{n}-\alpha_{n}\left(F u_{n}-v_{n}\right)-\theta_{n}\left(u_{n}-u_{1}\right), \\
v_{n+1}=v_{n}-\alpha_{n}\left(K v_{n}+u_{n}\right)-\theta_{n}\left(v_{n}-v_{1}\right), \quad n \in \mathbb{N} .
\end{gathered}
$$

Suppose that one of the following conditions holds:

$$
\begin{aligned}
& \text { (i) } \lim _{n \rightarrow \infty}\left(\frac{\alpha_{n}^{2}}{\theta_{n}}\right)=\lim _{n \rightarrow \infty} \alpha_{n}=0 \text {; } \\
& \text { (ii) } \lim _{n \rightarrow \infty}\left(\frac{\alpha_{n}}{\theta_{n}}\right)=0 .
\end{aligned}
$$

Then, the sequences $\left\{u_{n}\right\}_{n \in \mathbb{N}},\left\{v_{n}\right\}_{n \in \mathbb{N}},\left\{F u_{n}\right\}_{n \in \mathbb{N}}$, and $\left\{K v_{n}\right\}_{n \in \mathbb{N}}$ are bounded.

Remark 11. Corollary 9 is also a special case of Theorem 10.

Theorem 12. Let $H$ be a real Hilbert space. Let $F, K: H \rightarrow H$ be Lipschitz and monotone mappings. Suppose that $u+K F u=$ 0 has a solution in $H$. Let $\left\{\lambda_{n}\right\}_{n \in \mathbb{N}}$ be a sequence in $(0,1)$. Let $\left\{\alpha_{n}\right\}_{n \in \mathbb{N}}$ and $\left\{\theta_{n}\right\}_{n \in \mathbb{N}}$ be sequences in $(0,1]$. Let $\left\{u_{n}\right\}_{n \in \mathbb{N}}$ and $\left\{v_{n}\right\}_{n \in \mathbb{N}}$ be sequences in $H$ defined iteratively from arbitrary $u_{1}$, $v_{1} \in H$ by

$$
\begin{gathered}
u_{n+1}=u_{n}-\lambda_{n} \alpha_{n}\left(F u_{n}-v_{n}\right)-\lambda_{n} \theta_{n}\left(u_{n}-u_{1}\right), \\
v_{n+1}=v_{n}-\lambda_{n} \alpha_{n}\left(K v_{n}+u_{n}\right)-\lambda_{n} \theta_{n}\left(v_{n}-v_{1}\right), \quad n \in \mathbb{N} .
\end{gathered}
$$

Assume that

(i) $\sum_{n=1}^{\infty} \lambda_{n} \theta_{n}=\infty ; \lim _{n \rightarrow \infty} \lambda_{n} \alpha_{n}=\lim _{n \rightarrow \infty} \lambda_{n} \theta_{n}=0$;

(ii) one of the following conditions holds:

$$
\begin{aligned}
& \text { (a) } \lim _{n \rightarrow \infty}\left(\frac{\alpha_{n}^{2}}{\theta_{n}}\right)=0 \text {; } \\
& \text { (b) } \lim _{n \rightarrow \infty}\left(\frac{\lambda_{n}}{\theta_{n}}\right)=0 \text {; } \\
& \text { (c) } \lim _{n \rightarrow \infty}\left(\frac{\alpha_{n}}{\theta_{n}}\right)=0 \text {; }
\end{aligned}
$$

(iii) one of the following conditions holds:

$$
\begin{aligned}
& \text { (d) } \sum_{n=1}^{\infty} \lambda_{n}^{2} \alpha_{n}^{2}<\infty ; \\
& \text { (e) } \lim _{n \rightarrow \infty}\left(\frac{\lambda_{n} \alpha_{n}^{2}}{\theta_{n}}\right)=0 .
\end{aligned}
$$

Then, there exists a subset $K_{\min }$ of $H \times H$ such that if $(\bar{u}, \bar{v}) \epsilon$ $K_{\min }$ with $\bar{v}=F \bar{u}$, then the sequence $\left\{u_{n}\right\}$ converges strongly to $\bar{u}$. 
Proof. Let $B$ and $n_{0}$ be the same as the proof of Theorem 7 . Let $\mu$ be a Banach limit on $\ell^{\infty}$. Let $\left\{x_{n}\right\}_{n \in \mathbb{N}}$ be a sequence with $x_{1}=w_{1}$ and $x_{n}=w_{n_{0}+n-2}$ for each $n \geq 2$. Clearly, $\left\{x_{n}\right\}_{n \in \mathbb{N}} \subseteq B$. By Lemma 4 , there is a unique $x \in B$ such that

$$
\mu_{n}\left\|x_{n}-x\right\|^{2}=\min _{y \in B} \mu_{n}\left\|x_{n}-y\right\|^{2} .
$$

Let $K_{\min }=\{x\}$, and we assume that $\bar{w}=(\bar{u}, \bar{v}) \in K_{\min }$. Let $t \in[0,1]$. Then, $t w_{1}+(1-t) \bar{w} \in B$. Hence, for each $t \in(0,1)$, it follows from Lemma 1 that

$$
\begin{aligned}
\mu_{n}\left\|x_{n}-\bar{w}\right\|^{2} \leq & \mu_{n}\left\|x_{n}-t w_{1}-(1-t) \bar{w}\right\|^{2} \\
\leq & \mu_{n}\left\|x_{n}-\bar{w}\right\|^{2} \\
& -2 t \mu_{n}\left\langle w_{1}-\bar{w}, x_{n}-t w_{1}-(1-t) \bar{w}\right\rangle .
\end{aligned}
$$

By Lemma 5, there exists $z_{0} \in H$ such that $\mu_{n}\left\langle x_{n}, y\right\rangle=\left\langle z_{0}, y\right\rangle$ for each $y \in H$. By (29), for each $t \in(0,1)$,

$$
\begin{aligned}
\left\langle w_{1}\right. & \left.-\bar{w}, z_{0}-t w_{1}-(1-t) \bar{w}\right\rangle \\
& =\mu_{n}\left\langle w_{1}-\bar{w}, x_{n}-t w_{1}-(1-t) \bar{w}\right\rangle \leq 0 .
\end{aligned}
$$

In (30), letting $t \rightarrow 0$, we get

$$
\mu_{n}\left\langle w_{1}-\bar{w}, x_{n}-\bar{w}\right\rangle=\left\langle w_{1}-\bar{w}, z_{0}-\bar{w}\right\rangle \leq 0 .
$$

Clearly,

$$
\limsup _{n \rightarrow \infty}\left(\left\langle w_{1}-\bar{w}, x_{n+1}-\bar{w}\right\rangle-\left\langle w_{1}-\bar{w}, x_{n}-\bar{w}\right\rangle\right) \leq 0 .
$$

By (31), (32), and Lemma 3, we know that $\lim \sup _{n \rightarrow \infty}\left\langle w_{1}-\right.$ $\left.\bar{w}, x_{n}-\bar{w}\right\rangle \leq 0$.

Hence,

$$
\limsup _{n \rightarrow \infty}\left\langle w_{1}-\bar{w}, w_{n}-\bar{w}\right\rangle \leq 0 .
$$

By (17), (33), and Lemma 2, we know that $\lim _{n \rightarrow \infty}\left\|w_{n}-\bar{w}\right\|=$ 0 . Therefore, $\left\{u_{n}\right\}$ converges strongly to $\bar{u}$.

Remark 13. (i) The conclusion of Theorem 12 is still true if $\sum_{n=1}^{\infty} \lambda_{n} \theta_{n}=\infty, \lim _{n \rightarrow \infty}\left(\alpha_{n}^{2} / \theta_{n}\right)=0$, and $\lim _{n \rightarrow \infty} \lambda_{n} \alpha_{n}=$ $\lim _{n \rightarrow \infty} \lambda_{n} \theta_{n}=0$.

(ii) The conclusion of Theorem 12 is still true if $\sum_{n=1}^{\infty} \lambda_{n} \theta_{n}=\infty, \lim _{n \rightarrow \infty}\left(\alpha_{n} / \theta_{n}\right)=0$, and $\lim _{n \rightarrow \infty} \lambda_{n}=0$.

Remark 14. Following the same argument as in Remark 8, we know that Theorem 12 improves the conditions of [17, Theorem 3.2] if the space $E$ is reduced to a real Hilbert space.

In Theorem 12, if $\alpha_{n}=\theta_{n}=1$ and $\lambda_{n}=\beta_{n}$ for each $n \in \mathbb{N}$, then we have the following result.

Corollary 15. Let $H$ be a real Hilbert space. Let $F, K: H \rightarrow$ $H$ be Lipschitz and monotone mappings. Suppose that $u+$ $K F u=0$ has a solution $\bar{u}$ in $H$. Let $\left\{\beta_{n}\right\}_{n \in \mathbb{N}}$ be a sequence in $(0,1)$. Let $\left\{u_{n}\right\}_{n \in \mathbb{N}}$ and $\left\{v_{n}\right\}_{n \in \mathbb{N}}$ be sequences in $H$ defined iteratively from arbitrary $u_{1}, v_{1} \in H$ by

$$
\begin{gathered}
u_{n+1}=u_{n}-\beta_{n}\left(F u_{n}-v_{n}\right)-\beta_{n}\left(u_{n}-u_{1}\right), \\
v_{n+1}=v_{n}-\beta_{n}\left(K v_{n}+u_{n}\right)-\beta_{n}\left(v_{n}-v_{1}\right), \quad n \in \mathbb{N} .
\end{gathered}
$$

Assume that $\lim _{n \rightarrow \infty} \beta_{n}=0$ and $\sum_{n=1}^{\infty} \beta_{n}=\infty$. Then there exists a subset $K_{\min }$ of $H \times H$ such that if $(\bar{u}, \bar{v}) \in K_{\min }$ with $\bar{v}=F \bar{u}$, then the sequence $\left\{u_{n}\right\}$ converges strongly to $\bar{u}$.

In Theorem 12, if $\alpha_{n}=1$ for each $n \in \mathbb{N}$, then we have the following result.

Corollary 16. Let $H$ be a real Hilbert space. Let $F, K: H \rightarrow H$ be Lipschitz and monotone mappings. Suppose that $u+K F u=$ 0 has a solution in $H$. Let $\left\{\lambda_{n}\right\}_{n \in \mathbb{N}}$ be a sequence in $(0,1)$. Let $\left\{\theta_{n}\right\}_{n \in \mathbb{N}}$ be a sequence in $(0,1]$. Let $\left\{u_{n}\right\}_{n \in \mathbb{N}}$ and $\left\{v_{n}\right\}_{n \in \mathbb{N}}$ be sequences in $H$ defined iteratively from arbitrary $u_{1}, v_{1} \in H$ by

$$
\begin{gathered}
u_{n+1}=u_{n}-\lambda_{n}\left(F u_{n}-v_{n}\right)-\lambda_{n} \theta_{n}\left(u_{n}-u_{1}\right), \\
v_{n+1}=v_{n}-\lambda_{n}\left(K v_{n}+u_{n}\right)-\lambda_{n} \theta_{n}\left(v_{n}-v_{1}\right), \quad n \in \mathbb{N} .
\end{gathered}
$$

Assume that $\sum_{n=1}^{\infty} \lambda_{n} \theta_{n}=\infty, \lim _{n \rightarrow \infty} \lambda_{n} \theta_{n}=0$, and $\lim _{n \rightarrow \infty}\left(\lambda_{n} / \theta_{n}\right)=0$. Then, there exists a subset $K_{\min }$ of $H \times H$ such that if $(\bar{u}, \bar{v}) \in K_{\min }$ with $\bar{v}=F \bar{u}$, then the sequence $\left\{u_{n}\right\}$ converges strongly to $\bar{u}$.

In fact, following the same argument as the proof of Theorem 12, we get the following result.

Theorem 17. Let $H$ be a real Hilbert space. Let $F, K: H \rightarrow H$ be Lipschitz and monotone mappings. Suppose that $u+K F u=$ 0 has a solution in $H$. Let $\left\{\alpha_{n}\right\}_{n \in \mathbb{N}}$ and $\left\{\theta_{n}\right\}_{n \in \mathbb{N}}$ be sequences in $(0,1]$. Let $\left\{u_{n}\right\}_{n \in \mathbb{N}}$ and $\left\{v_{n}\right\}_{n \in \mathbb{N}}$ be sequences in $H$ defined iteratively from arbitrary $u_{1}, v_{1} \in H$ by

$$
\begin{gathered}
u_{n+1}=u_{n}-\alpha_{n}\left(F u_{n}-v_{n}\right)-\theta_{n}\left(u_{n}-u_{1}\right), \\
v_{n+1}=v_{n}-\alpha_{n}\left(K v_{n}+u_{n}\right)-\theta_{n}\left(v_{n}-v_{1}\right), \quad n \in \mathbb{N} .
\end{gathered}
$$

Assume that $\sum_{n=1}^{\infty} \theta_{n}=\infty, \lim _{n \rightarrow \infty} \theta_{n}=0$, and $\lim _{n \rightarrow \infty}\left(\alpha_{n}^{2} /\right.$ $\left.\theta_{n}\right)=0$. Then, there exists a subset $K_{\min }$ of $H \times H$ such that if $(\bar{u}, \bar{v}) \in K_{\min }$ with $\bar{v}=F \bar{u}$, then the sequence $\left\{u_{n}\right\}$ converges strongly to $\bar{u}$.

Remark 18. Corollary 15 is also a special case of Theorem 17.

\section{Main Results (II)}

In this section, we consider that $F$ and $K$ are bounded mappings.

Theorem 19. Let $H$ be a real Hilbert space. Let $F, K: H \rightarrow H$ be bounded and monotone mappings. Suppose that $u+K F u=0$ has a solution in $H$. Let $\left\{\lambda_{n}\right\}_{n \in \mathbb{N}}$ be a sequence in $(0,1)$. Let $\left\{\alpha_{n}\right\}_{n \in \mathbb{N}}$ and $\left\{\theta_{n}\right\}_{n \in \mathbb{N}}$ be sequences in $(0,1]$. Let $\left\{u_{n}\right\}_{n \in \mathbb{N}}$ and 
$\left\{v_{n}\right\}_{n \in \mathbb{N}}$ be sequences in $H$ defined iteratively from arbitrary $u_{1}$, $v_{1} \in H$ by

$$
\begin{gathered}
u_{n+1}=u_{n}-\lambda_{n} \alpha_{n}\left(F u_{n}-v_{n}\right)-\lambda_{n} \theta_{n}\left(u_{n}-u_{1}\right), \\
v_{n+1}=v_{n}-\lambda_{n} \alpha_{n}\left(K v_{n}+u_{n}\right)-\lambda_{n} \theta_{n}\left(v_{n}-v_{1}\right), \quad n \in \mathbb{N} .
\end{gathered}
$$

Suppose that one of the following conditions holds:

$$
\begin{aligned}
& \text { (i) } \lim _{n \rightarrow \infty}\left(\frac{\alpha_{n}^{2}}{\theta_{n}}\right)=\lim _{n \rightarrow \infty} \lambda_{n} \alpha_{n}=0 ; \\
& \text { (ii) } \lim _{n \rightarrow \infty}\left(\frac{\lambda_{n}}{\theta_{n}}\right)=0 ; \\
& \text { (iii) } \lim _{n \rightarrow \infty}\left(\frac{\lambda_{n}}{\theta_{n}}\right)=\lim _{n \rightarrow \infty} \lambda_{n} \alpha_{n}=0 \text {; } \\
& \text { (iv) } \lim _{n \rightarrow \infty}\left(\frac{\alpha_{n}}{\theta_{n}}\right)=0 .
\end{aligned}
$$

Then, the sequences $\left\{u_{n}\right\}_{n \in \mathbb{N}},\left\{v_{n}\right\}_{n \in \mathbb{N}},\left\{F u_{n}\right\}_{n \in \mathbb{N}}$, and $\left\{K v_{n}\right\}_{n \in \mathbb{N}}$ are bounded.

Proof. Since $F$ and $K$ are bounded, we know that $A$ is bounded. Hence, $\|A\|<\infty$. From the proof of Theorem 7 , we know that

$$
\begin{aligned}
& \| w_{n+1}-\bar{w} \|^{2} \\
& \leq\left(1-\lambda_{n} \theta_{n}\right)\left\|w_{n}-\bar{w}\right\|^{2}+2 \lambda_{n} \theta_{n}\left\langle w_{1}-\bar{w}, w_{n+1}-\bar{w}\right\rangle \\
&+2 \lambda_{n} \alpha_{n}\left\|A w_{n}\right\| \cdot\left(\lambda_{n} \alpha_{n}\left\|A w_{n}\right\|+\lambda_{n} \theta_{n}\left\|w_{n}-w_{1}\right\|\right) \\
& \leq\left(1-\lambda_{n} \theta_{n}\right)\left\|w_{n}-\bar{w}\right\|^{2}+2 \lambda_{n} \theta_{n}\left\langle w_{1}-\bar{w}, w_{n+1}-\bar{w}\right\rangle \\
& \quad+2 \lambda_{n}^{2} \alpha_{n}^{2}\|A\|^{2} \cdot\left\|w_{n}\right\|^{2}+2 \lambda_{n}^{2} \alpha_{n} \theta_{n}\|A\| \cdot\left\|w_{n}\right\| \cdot\left\|w_{n}-w_{1}\right\|
\end{aligned}
$$

for each $n \in \mathbb{N}$.

Choose $r_{0}>0$ such that $\max \left\{\left\|w_{1}\right\|,\|\bar{w}\|\right\} \leq r_{0} / 8$. For conditions (i)-(iv), we only need to consider one case since the proof is similar. Now, we assume that $\lim _{n \rightarrow \infty}\left(\lambda_{n} / \theta_{n}\right)=$ 0 . Then, there exists $n_{0} \in \mathbb{N}$ such that

$$
\frac{\lambda_{n}}{\theta_{n}}<\max \left\{\frac{8}{81\|A\|^{2}}, \frac{1}{10\|A\|}\right\}
$$

for each $n \geq n_{0}$. Choose $r>1$ such that $r_{0}<r$ and $\left\|w_{n_{0}}\right\| \leq$ $r / 8$. Let $B:=B(\bar{w}, r)$. Clearly, $\left\|w_{n_{0}}-\bar{w}\right\| \leq r / 4$.

Now, we want to show that $w_{n} \in B$ for each $n \geq n_{0}$. Clearly, $w_{n_{0}} \in B(\bar{w}, r)$. Suppose that $w_{n} \in B$ for some $n \geq n_{0}$. Then, $w_{n+1} \in B$. Indeed, if not, then we have

$$
\left\|w_{n}-\bar{w}\right\| \leq r<\left\|w_{n+1}-\bar{w}\right\|
$$

Clearly, $\left\|w_{n}\right\| \leq\left\|w_{n}-\bar{w}\right\|+\|\bar{w}\| \leq 9 r / 8$. Hence, by (39) and (41), we get

$$
\begin{aligned}
\| w_{n+1} & -\bar{w} \|^{2} \\
\leq & \left(1-\lambda_{n} \theta_{n}\right)\left\|w_{n}-\bar{w}\right\|^{2}+2 \lambda_{n} \theta_{n}\left\|w_{1}-\bar{w}\right\| \cdot\left\|w_{n+1}-\bar{w}\right\| \\
& +2 \lambda_{n}^{2} \alpha_{n}^{2}\|A\|^{2} \cdot\left\|w_{n}\right\|^{2}+2 \lambda_{n}^{2} \alpha_{n} \theta_{n}\|A\| \cdot\left\|w_{n}\right\| \cdot\left\|w_{n}-w_{1}\right\| \\
\leq & \left(1-\lambda_{n} \theta_{n}\right) r^{2}+2 \lambda_{n} \theta_{n} \frac{r}{4} \cdot\left\|w_{n+1}-\bar{w}\right\| \\
& +2 \lambda_{n}^{2} \alpha_{n}^{2}\|A\|^{2} \cdot \frac{81}{64} r^{2}+2 \lambda_{n}^{2} \alpha_{n} \theta_{n}\|A\| \cdot \frac{10}{8} r^{2} \\
\leq & \left(1-\lambda_{n} \theta_{n}\right)\left\|w_{n+1}-\bar{w}\right\|^{2}+\lambda_{n} \theta_{n} \frac{r}{2} \cdot\left\|w_{n+1}-\bar{w}\right\| \\
& +\lambda_{n}^{2} \alpha_{n}^{2}\|A\|^{2} \cdot \frac{81}{32} r^{2}+\lambda_{n}^{2} \alpha_{n} \theta_{n}\|A\| \cdot \frac{5}{2} r^{2} .
\end{aligned}
$$

This implies that

$$
\begin{aligned}
\left\|w_{n+1}-\bar{w}\right\|^{2} \leq & \frac{r}{2} \cdot\left\|w_{n+1}-\bar{w}\right\|+\frac{81}{32} \cdot \frac{\lambda_{n} \alpha_{n}^{2}}{\theta_{n}}\|A\|^{2} \cdot r^{2} \\
& +\frac{5}{2} \cdot \frac{\lambda_{n} \alpha_{n} \theta_{n}}{\theta_{n}}\|A\| \cdot r^{2} .
\end{aligned}
$$

Furthermore, we get

$$
\begin{aligned}
r<\left\|w_{n+1}-\bar{w}\right\| & \leq \frac{r}{2}+\frac{81}{32} \frac{\lambda_{n} \alpha_{n}^{2}}{\theta_{n}}\|A\|^{2} \cdot r+\frac{5}{2} \cdot \frac{\lambda_{n} \alpha_{n} \theta_{n}}{\theta_{n}}\|A\| \cdot r \\
& \leq \frac{r}{2}+\frac{81}{32} \frac{\lambda_{n}}{\theta_{n}}\|A\|^{2} \cdot r+\frac{5}{2} \cdot \frac{\lambda_{n}}{\theta_{n}}\|A\| \cdot r \\
& \leq r .
\end{aligned}
$$

This leads to a contradiction. So, $w_{n+1} \in B$. Hence, by mathematical induction, we know that $\left\{w_{n}\right\}_{n \geq n_{0}} \subseteq B$. Therefore, $\left\{u_{n}\right\}_{n \in \mathbb{N}}$ and $\left\{v_{n}\right\}_{n \in \mathbb{N}}$ are bounded sequences. Furthermore, $\left\{F u_{n}\right\}_{n \in \mathbb{N}}$ and $\left\{K v_{n}\right\}_{n \in \mathbb{N}}$ are bounded sequences since $F$ and $K$ are bounded mappings.

Remark 20. (i) Theorem 19 improves the conditions of [9, Theorem 3.1] if the space $E$ is reduced to a real Hilbert space. Indeed, [9, Theorem 3.1] assumes that $\lim _{n \rightarrow \infty}\left(\lambda_{n} / \theta_{n}\right)=$ $\lim _{n \rightarrow \infty}\left(\alpha_{n} / \theta_{n}\right)=0$.

(ii) Furthermore, we know that it is impossible to assume that $\alpha_{n}=\theta_{n}=1$ in [9, Theorem 3.1]. However, we can choose $\alpha_{n}=\theta_{n}=1$ in our result. Indeed, if $\alpha_{n}=\theta_{n}=1$ and $\lambda_{n}=\beta_{n}$, then we have the following result as special case of Theorem 19.

Corollary 21. Let $H$ be a real Hilbert space. Let $F, K: H \rightarrow H$ be bounded and monotone mappings. Suppose that $u+K F u=$ 0 has a solution in $H$. Let $\left\{\beta_{n}\right\}_{n \in \mathbb{N}}$ be a sequence in $(0,1)$. 
Let $\left\{u_{n}\right\}_{n \in \mathbb{N}}$ and $\left\{v_{n}\right\}_{n \in \mathbb{N}}$ be sequences in $H$ defined iteratively from arbitrary $u_{1}, v_{1} \in H$ by

$$
\begin{gathered}
u_{n+1}=u_{n}-\beta_{n}\left(F u_{n}-v_{n}\right)-\beta_{n}\left(u_{n}-u_{1}\right), \\
v_{n+1}=v_{n}-\beta_{n}\left(K v_{n}+u_{n}\right)-\beta_{n}\left(v_{n}-v_{1}\right), \quad n \in \mathbb{N} .
\end{gathered}
$$

If $\lim _{n \rightarrow \infty} \beta_{n}=0$, then the sequences $\left\{u_{n}\right\}_{n \in \mathbb{N}},\left\{v_{n}\right\}_{n \in \mathbb{N}}$, $\left\{F u_{n}\right\}_{n \in \mathbb{N}}$, and $\left\{K v_{n}\right\}_{n \in \mathbb{N}}$ are bounded.

Following the same argument as the proof of Theorem 19, we get the following result. Note that Corollary 21 is also a special case of the following result.

Theorem 22. Let $H$ be a real Hilbert space. Let $F, K: H \rightarrow H$ be bounded and monotone mappings. Suppose that $u+K F u=$ 0 has a solution in $H$. Let $\left\{\alpha_{n}\right\}_{n \in \mathbb{N}}$ and $\left\{\theta_{n}\right\}_{n \in \mathbb{N}}$ be sequences in $(0,1]$. Let $\left\{u_{n}\right\}_{n \in \mathbb{N}}$ and $\left\{v_{n}\right\}_{n \in \mathbb{N}}$ be sequences in $H$ defined iteratively from arbitrary $u_{1}, v_{1} \in H$ by

$$
\begin{gathered}
u_{n+1}=u_{n}-\alpha_{n}\left(F u_{n}-v_{n}\right)-\theta_{n}\left(u_{n}-u_{1}\right), \\
v_{n+1}=v_{n}-\alpha_{n}\left(K v_{n}+u_{n}\right)-\theta_{n}\left(v_{n}-v_{1}\right), \quad n \in \mathbb{N} .
\end{gathered}
$$

Suppose that one of the following conditions holds:

$$
\begin{aligned}
& \text { (i) } \lim _{n \rightarrow \infty}\left(\frac{\alpha_{n}^{2}}{\theta_{n}}\right)=\lim _{n \rightarrow \infty} \alpha_{n}=0 ; \\
& \text { (ii) } \lim _{n \rightarrow \infty}\left(\frac{\alpha_{n}}{\theta_{n}}\right)=0 .
\end{aligned}
$$

Then, the sequences $\left\{u_{n}\right\}_{n \in \mathbb{N}},\left\{v_{n}\right\}_{n \in \mathbb{N}},\left\{F u_{n}\right\}_{n \in \mathbb{N}}$, and $\left\{K v_{n}\right\}_{n \in \mathbb{N}}$ are bounded.

Following the similar argument as the proof of Theorem 12, we get the following result.

Theorem 23. Let $H$ be a real Hilbert space. Let $F, K: H \rightarrow H$ be bounded and monotone mappings. Suppose that $u+K F u=0$ has a solution in $H$. Let $\left\{\lambda_{n}\right\}_{n \in \mathbb{N}}$ be a sequence in $(0,1)$. Let $\left\{\alpha_{n}\right\}_{n \in \mathbb{N}}$ and $\left\{\theta_{n}\right\}_{n \in \mathbb{N}}$ be sequences in $(0,1]$. Let $\left\{u_{n}\right\}_{n \in \mathbb{N}}$ and $\left\{v_{n}\right\}_{n \in \mathbb{N}}$ be sequences in $H$ defined iteratively from arbitrary $u_{1}$, $v_{1} \in H$ by

$$
\begin{gathered}
u_{n+1}=u_{n}-\lambda_{n} \alpha_{n}\left(F u_{n}-v_{n}\right)-\lambda_{n} \theta_{n}\left(u_{n}-u_{1}\right), \\
v_{n+1}=v_{n}-\lambda_{n} \alpha_{n}\left(K v_{n}+u_{n}\right)-\lambda_{n} \theta_{n}\left(v_{n}-v_{1}\right), \quad n \in \mathbb{N} .
\end{gathered}
$$

Assume that

(i) $\sum_{n=1}^{\infty} \lambda_{n} \theta_{n}=\infty ; \lim _{n \rightarrow \infty} \lambda_{n} \alpha_{n}=\lim _{n \rightarrow \infty} \lambda_{n} \theta_{n}=0$;

(ii) one of the following conditions holds:

$$
\begin{aligned}
& \text { (a) } \lim _{n \rightarrow \infty}\left(\frac{\alpha_{n}^{2}}{\theta_{n}}\right)=0 \text {; } \\
& \text { (b) } \lim _{n \rightarrow \infty}\left(\frac{\lambda_{n}}{\theta_{n}}\right)=0 \text {; } \\
& \text { (c) } \lim _{n \rightarrow \infty}\left(\frac{\alpha_{n}}{\theta_{n}}\right)=0 ;
\end{aligned}
$$

(iii) one of the following conditions holds:

$$
\begin{aligned}
& \text { (d) } \sum_{n=1}^{\infty} \lambda_{n}^{2} \alpha_{n}^{2}<\infty ; \quad \sum_{n=1}^{\infty} \lambda_{n}^{2} \alpha_{n} \theta_{n}<\infty ; \\
& \text { (e) } \sum_{n=1}^{\infty} \lambda_{n}^{2} \alpha_{n}<\infty ; \\
& \text { (f) } \lim _{n \rightarrow \infty}\left(\frac{\lambda_{n} \alpha_{n}^{2}}{\theta_{n}}\right)=0 .
\end{aligned}
$$

Then, there exists a subset $K_{\min }$ of $H \times H$ such that if $(\bar{u}, \bar{v}) \epsilon$ $K_{\min }$ with $\bar{v}=F \bar{u}$, then the sequence $\left\{u_{n}\right\}$ converges strongly to $\bar{u}$.

Remark 24. (i) The conclusion of Theorem 23 is still true if $\sum_{n=1}^{\infty} \lambda_{n} \theta_{n}=\infty, \lim _{n \rightarrow \infty}\left(\alpha_{n}^{2} / \theta_{n}\right)=0$, and $\lim _{n \rightarrow \infty} \lambda_{n} \alpha_{n}=$ $\lim _{n \rightarrow \infty} \lambda_{n} \theta_{n}=0$. Furthermore, the conclusion of Theorem 23 is still true if $\sum_{n=1}^{\infty} \lambda_{n} \theta_{n}=\infty, \lim _{n \rightarrow \infty}\left(\alpha_{n} / \theta_{n}\right)=0$, and $\lim _{n \rightarrow \infty} \lambda_{n}=0$.

(ii) Theorem 23 improves the conditions of [9, Theorem 3.2] if the space $E$ is reduced to a real Hilbert space. Indeed, [9, Theorem 3.2] assumes that $\lim _{n \rightarrow \infty}\left(\lambda_{n} / \theta_{n}\right)=$ $\lim _{n \rightarrow \infty}\left(\alpha_{n} / \theta_{n}\right)=0$.

The following is a special case of Theorem 23.

Corollary 25. Let $H$ be a real Hilbert space. Let $F, K$ : $H \rightarrow H$ be bounded and monotone mappings. Suppose that $u+K F u=0$ has a solution in $H$. Let $\left\{\beta_{n}\right\}_{n \in \mathbb{N}}$ be a sequence in $(0,1)$. Let $\left\{u_{n}\right\}_{n \in \mathbb{N}}$ and $\left\{v_{n}\right\}_{n \in \mathbb{N}}$ be sequences in $H$ defined iteratively from arbitrary $u_{1}, v_{1} \in H$ by

$$
\begin{gathered}
u_{n+1}=u_{n}-\beta_{n}\left(F u_{n}-v_{n}\right)-\beta_{n}\left(u_{n}-u_{1}\right), \\
v_{n+1}=v_{n}-\beta_{n}\left(K v_{n}+u_{n}\right)-\beta_{n}\left(v_{n}-v_{1}\right), \quad n \in \mathbb{N} .
\end{gathered}
$$

Assume that $\sum_{n=1}^{\infty} \beta_{n}=\infty$ and $\lim _{n \rightarrow \infty} \beta_{n}=0$. Then, there exists a subset $K_{\min }$ of $H \times H$ such that if $(\bar{u}, \bar{v}) \in K_{\min }$ with $\bar{v}=F \bar{u}$, then the sequence $\left\{u_{n}\right\}$ converges strongly to $\bar{u}$.

The following is also a special case of Theorem 23.

Corollary 26. Let $H$ be a real Hilbert space. Let $F, K: H \rightarrow H$ be bounded and monotone mappings. Suppose that $u+K F u=0$ has a solution in $H$. Let $\left\{\lambda_{n}\right\}_{n \in \mathbb{N}}$ be a sequence in $(0,1)$. Let $\left\{\theta_{n}\right\}_{n \in \mathbb{N}}$ be a sequence in $(0,1]$. Let $\left\{u_{n}\right\}_{n \in \mathbb{N}}$ and $\left\{v_{n}\right\}_{n \in \mathbb{N}}$ be sequences in $H$ defined iteratively from arbitrary $u_{1}, v_{1} \in H$ by

$$
\begin{gathered}
u_{n+1}=u_{n}-\lambda_{n} \alpha_{n}\left(F u_{n}-v_{n}\right)-\lambda_{n} \theta_{n}\left(u_{n}-u_{1}\right), \\
v_{n+1}=v_{n}-\lambda_{n} \alpha_{n}\left(K v_{n}+u_{n}\right)-\lambda_{n} \theta_{n}\left(v_{n}-v_{1}\right), \quad n \in \mathbb{N} .
\end{gathered}
$$

Assume that $\sum_{n=1}^{\infty} \lambda_{n} \theta_{n}=\infty, \lim _{n \rightarrow \infty} \lambda_{n} \theta_{n}=0$, and $\lim _{n \rightarrow \infty}\left(\lambda_{n} / \theta_{n}\right)=0$. Then, there exists a subset $K_{\min }$ of $H \times H$ such that if $(\bar{u}, \bar{v}) \in K_{\min }$ with $\bar{v}=F \bar{u}$, then the sequence $\left\{u_{n}\right\}$ converges strongly to $\bar{u}$. 
Furthermore, we get the following result. Note that Corollary 25 is also a special case of the following result.

Theorem 27. Let $H$ be a real Hilbert space. Let $F, K: H \rightarrow H$ be bounded and monotone mappings. Suppose that $u+K F u=$ 0 has a solution in $H$. Let $\left\{\alpha_{n}\right\}_{n \in \mathbb{N}}$ and $\left\{\theta_{n}\right\}_{n \in \mathbb{N}}$ be sequences in $(0,1]$. Let $\left\{u_{n}\right\}_{n \in \mathbb{N}}$ and $\left\{v_{n}\right\}_{n \in \mathbb{N}}$ be sequences in $H$ defined iteratively from arbitrary $u_{1}, v_{1} \in H$ by

$$
\begin{gathered}
u_{n+1}=u_{n}-\alpha_{n}\left(F u_{n}-v_{n}\right)-\theta_{n}\left(u_{n}-u_{1}\right), \\
v_{n+1}=v_{n}-\alpha_{n}\left(K v_{n}+u_{n}\right)-\theta_{n}\left(v_{n}-v_{1}\right), \quad n \in \mathbb{N} .
\end{gathered}
$$

Assume that $\sum_{n=1}^{\infty} \theta_{n}=\infty, \lim _{n \rightarrow \infty} \theta_{n}=0$, and $\lim _{n \rightarrow \infty}\left(\alpha_{n}^{2} /\right.$ $\left.\theta_{n}\right)=0$. Then, there exists a subset $K_{\min }$ of $H \times H$ such that if $(\bar{u}, \bar{v}) \in K_{\min }$ with $\bar{v}=F \bar{u}$, then the sequence $\left\{u_{n}\right\}$ converges strongly to $\bar{u}$.

\section{References}

[1] A. Hammerstein, "Nichtlineare integralgleichungen nebst anwendungen," Acta Mathematica, vol. 54, no. 1, pp. 117-176, 1930.

[2] H. Brézis and F. E. Browder, "Some new results about Hammerstein equations," Bulletin of the American Mathematical Society, vol. 80, pp. 567-572, 1974.

[3] H. Brezis and F. E. Browder, "Existence theorems for nonlinear integral equations of Hammerstein type," Bulletin of the American Mathematical Society, vol. 81, pp. 73-78, 1975.

[4] H. Brézis and F. E. Browder, "Nonlinear integral equations and systems of Hammerstein type," Advances in Mathematics, vol. 18, no. 2, pp. 115-147, 1975.

[5] F. E. Browder, D. G. de Figueiredo, and C. P. Gupta, "Maximal monotone operators and nonlinear integral equations of Hammerstein type," Bulletin of the American Mathematical Society, vol. 76, pp. 700-705, 1970.

[6] F. E. Browder and C. P. Gupta, "Monotone operators and nonlinear integral equations of Hammerstein type," Bulletin of the American Mathematical Society, vol. 75, pp. 1347-1353, 1969.

[7] V. Dolezal, Monotone Operators and Applications in Control and Network Theory, vol. 2 of Studies in Automation and Control, Elsevier Scientific Publishing, Amsterdam, The Netherlands, 1979.

[8] C. E. Chidume and H. Zegeye, "Approximation of solutions of nonlinear equations of Hammerstein type in Hilbert space," Proceedings of the American Mathematical Society, vol. 133, no. 3, pp. 851-858, 2005.

[9] C. E. Chidume and E. U. Ofoedu, "Solution of nonlinear integral equations of Hammerstein type," Nonlinear Analysis: Theory, Methods \& Applications, vol. 74, no. 13, pp. 4293-4299, 2011.

[10] C. E. Chidume and N. Djitté, "Approximation of solutions of nonlinear integral equations of Hammerstein type," ISRN Mathematical Analysis, vol. 2012, Article ID 169751, 12 pages, 2012.

[11] K. Aoyama, Y. Kimura, W. Takahashi, and M. Toyoda, "Approximation of common fixed points of a countable family of nonexpansive mappings in a Banach space," Nonlinear Analysis: Theory, Methods \& Applications, vol. 67, no. 8, pp. 2350-2360, 2007.

[12] W. Takahashi, Nonlinear Functional Analysis. Fixed Point Theory and Its Applications, Yokohama Publishers, Yokohama, Japan, 2000 .
[13] N. Shioji and W. Takahashi, "Strong convergence of approximated sequences for nonexpansive mappings in Banach spaces," Proceedings of the American Mathematical Society, vol. 125, no. 12, pp. 3641-3645, 1997.

[14] W. Takahashi and J.-C. Yao, "Fixed point theorems and ergodic theorems for nonlinear mappings in Hilbert spaces," Taiwanese Journal of Mathematics, vol. 15, no. 2, pp. 457-472, 2011.

[15] T. Kawasaki and W. Takahashi, "Fixed point and nonlinear ergodic theorems for new nonlinear mappings in Hilbert spaces," Journal of Nonlinear and Convex Analysis, vol. 13, pp. 529-540, 2012.

[16] C. Chidume, Geometric Properties of Banach Spaces and Nonlinear Iterations, vol. 1965 of Lecture Notes in Mathematics, Springer, London, UK, 2009.

[17] N. Djitte and M. Sene, "Approximation of solutions of nonlinear integral equations of Hammerstein type with Lipschitz and bounded nonlinear operators," ISRN Applied Mathematics, vol. 2012, Article ID 963802, 15 pages, 2012. 


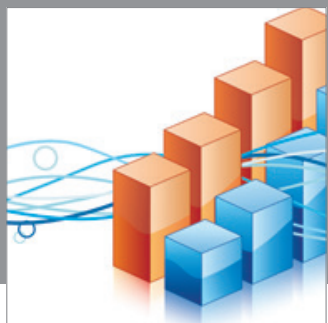

Advances in

Operations Research

mansans

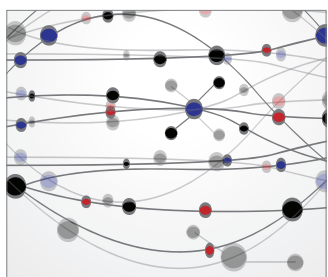

The Scientific World Journal
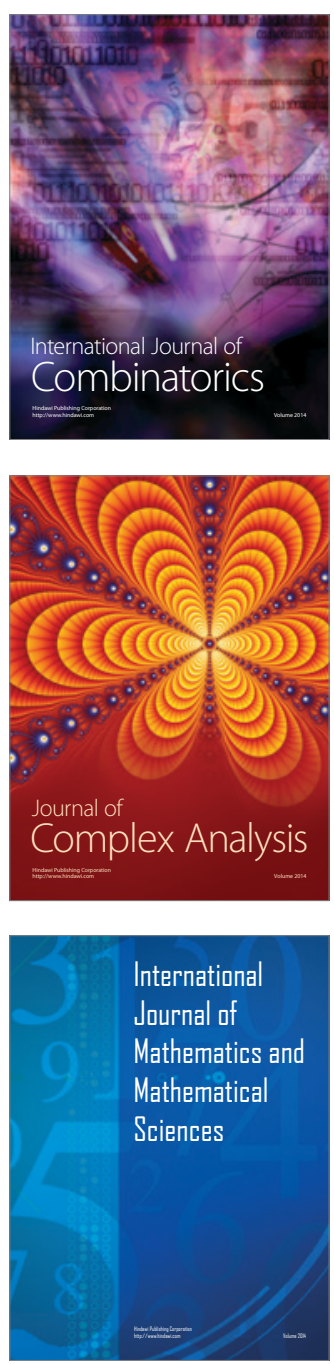
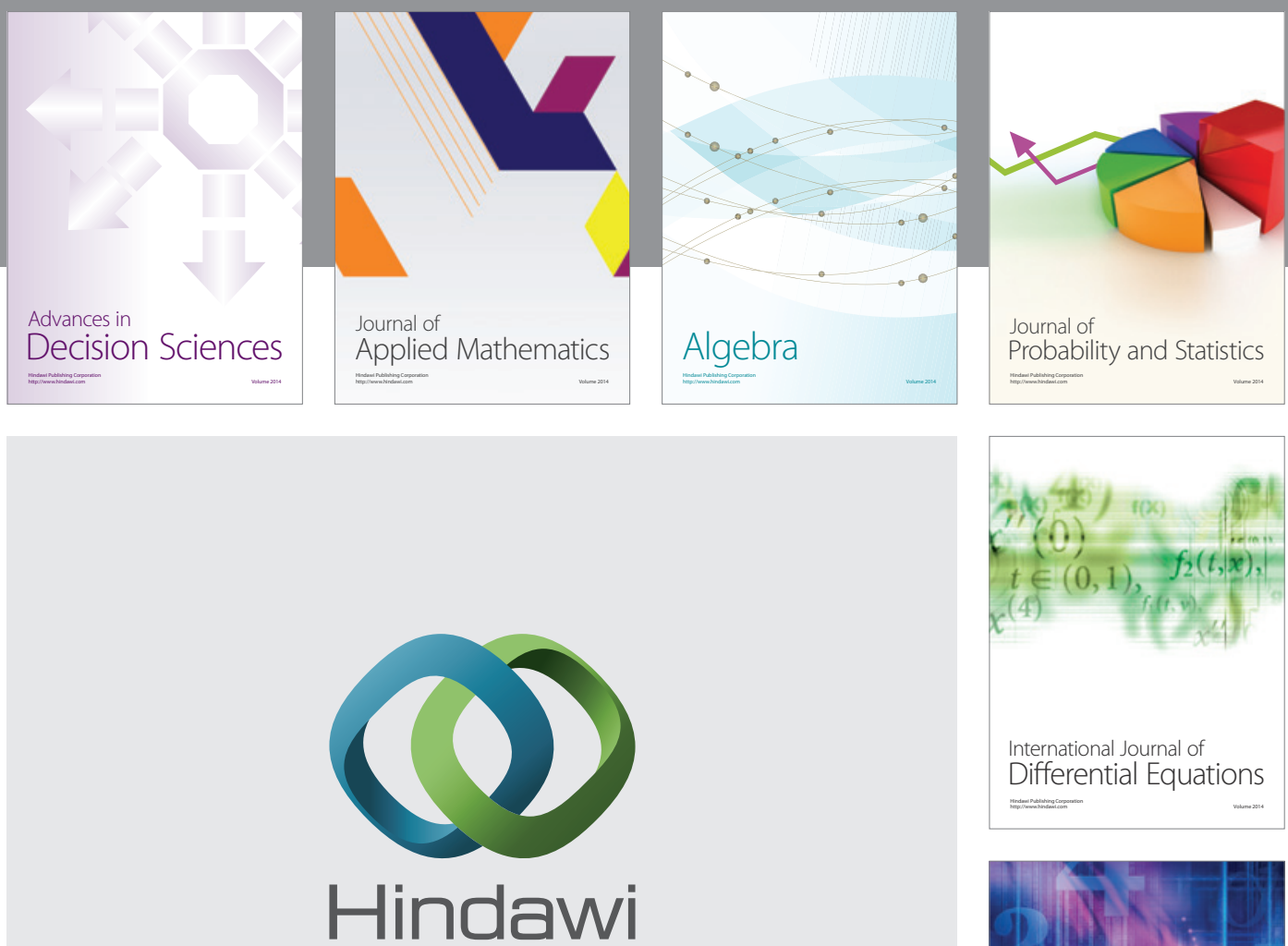

Submit your manuscripts at http://www.hindawi.com
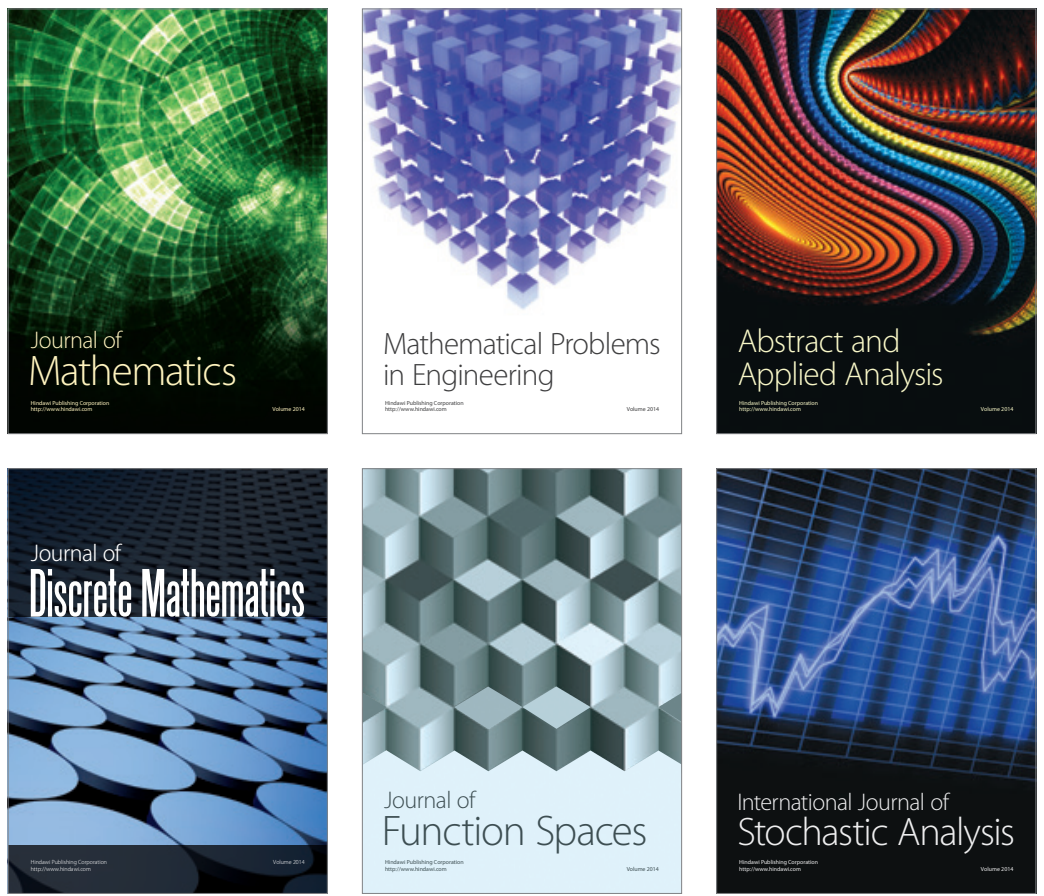

Journal of

Function Spaces

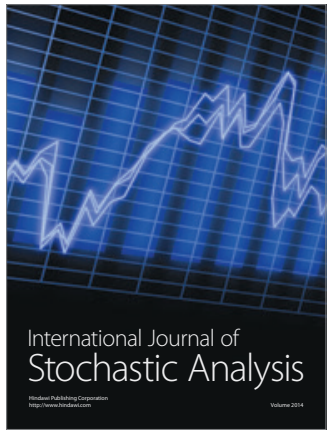

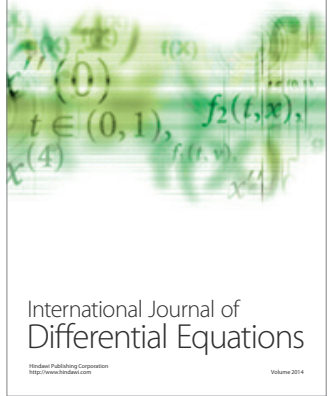
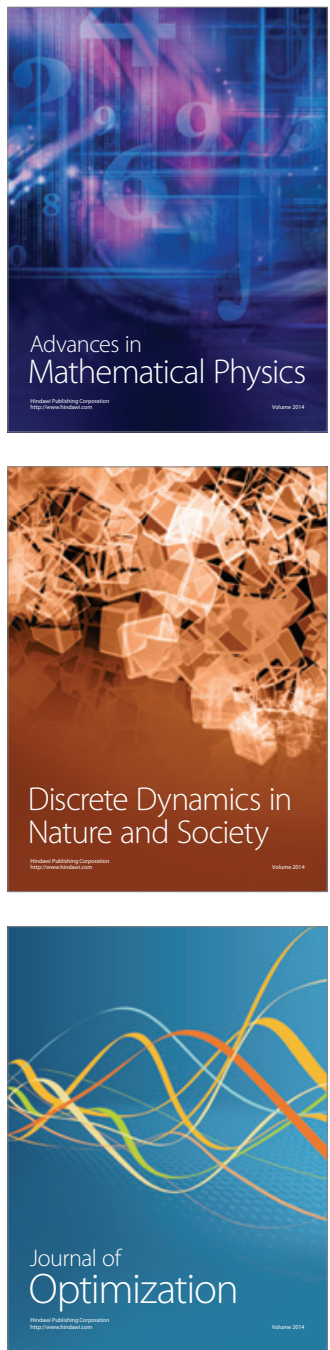